\title{
Texto e contexto: Gramsci e a história
}

AGGIO, Alberto; HENRIQUES, Luiz Sérgio; VACCA, Giuseppe (Orgs.). Gramsci no seu tempo. Tradução de Luiz Sérgio Henriques. Brasília: Fundação Astrogildo Pereira. Coedição, Rio de Janeiro: Contraponto, 2010. 414p.

\section{Cézar de Alencar Arnaut de Toledo*} Jarbas Mauricio Gomes**

Hegemonia, intelectuais, Estado ampliado, sociedade civil e sociedade política são alguns dos conceitos presentes nas obras de Antonio Gramsci (1891-1937) e que são encontrados em um número significativo de pesquisas na área das Ciências Sociais e Humanas. Os escritos de Antonio Gramsci tem se consagrado como um referencial teórico e metodológico nas pesquisas brasileiras, servindo ora de objeto de estudo, ora de fundamentação teórica. Na última década, o uso de seu pensamento como referencial de pesquisa foi retomado sob a influência da publicação da nova edição brasileira de sua obra que, ocorrida entre os anos de 1999 e 2002, teve o mérito de apresentar uma visão geral de seus escritos ao tornar acessíveis textos até então inéditos no Brasil.

O uso das ideias de Gramsci como referencial teórico passou a ser complementado com o aumento do número de pesquisas cujo objeto de estudo era o seu pensamento e a sua obra. A produção de conhecimentos sobre Gramsci nos diferentes campos das Ciências Sociais e Humanas reafirmou a tradição dos estudos gramscianos e valorizou a perspectiva de que é necessário investigar com profundidade a relação entre seus escritos e o contexto histórico a partir do qual foram elaborados para, então, mediante a compreensão historicamente contextualizada, promover a aplicação de suas análises e categorias conceituais à realidade brasileira.

O desenvolvimento das pesquisas sobre Gramsci e seu pensamento pode ser dividido em duas fases que se confundem, entrelaçam e se complementam. A primeira fase esteve

*Doutor em Educação pela UNICAMP (1996). Professor do Departamento de Fundamentos da Educação e do Programa de Pós-Graduação em Educação da Universidade Estadual de Maringá (PR).

** Mestre em Educação pela Universidade Estadual de Maringá (2012). Especialista em Pesquisa Educacional (UEM - 2009), graduado em Filosofia pela Universidade Estadual do Oeste do Paraná (2004). Professor de Filosofia para a Educação Básica. 
voltada ao estudo filológico de seus escritos, em especial dos Cadernos do Cárcere, para reconstruir a estrutura do pensamento gramsciano e estabelecer o caminho teórico percorrido por ele na construção de seus argumentos. Na segunda fase, os estudos estão voltados para a contextualização das ideias de Gramsci pelo movimento histórico em que os escritos foram produzidos.

Gramsci no seu tempo é uma publicação da Fundação Astrojildo Pereira em parceria com a Editora Contraponto e apresenta uma contribuição significativa para os avanços dos estudos gramscianos no Brasil e, em especial, para aqueles que se propõem a utilizar Gramsci como referencial teórico de pesquisa. Organizado por Alberto Aggio, Luiz Sérgio Henriques e Giuseppe Vacca, Gramsci no seu tempo está inscrito em uma proposta de estudos do pensamento de Gramsci que considera os limites históricos no qual foi produzido. Os 13 ensaios que compõem a obra ocupam 414 páginas e foram elaborados por estudiosos ligados ao Instituto Gramsci cujas perspectivas de leitura apontam elementos interessantes para a interpretação do pensamento de Gramsci. Um desses elementos, talvez o central deste conjunto de textos, é a valorização do conceito de revolução passiva como uma chave interpretativa do pensamento gramsciano. O deslocamento do eixo de leitura que tal proposta promove se contrapõe à leitura mais praticada, no caso do Brasil especificamente, na qual a chave de leitura mais utilizada foi, e talvez ainda seja, a concepção de hegemonia.

Gramsci no seu tempo foi organizado inicialmente por Francesco de Giasi e publicado na Itália pela Editora Carocci no ano de 2008, sob o título de Gramsci nel suo tempo. Originalmente a obra foi composta por dois volumes que apresentaram as contribuições teóricas de um Congresso de nome homônimo, realizado em Dezembro de 2007 na Itália. O congresso faz parte de uma tradição de estudos sob a coordenação da Fundação Instituto Gramsci que, em parceria com outros Institutos, Fundações e Universidades, a cada decênio da morte de Gramsci promove seminários e congressos para atualizar os estudos sobre a sua obra.

A edição brasileira de Gramsci no seu tempo foi traduzida do italiano para o português por Luiz Sérgio Henriques e não é uma reprodução integral da edição italiana. Os organizadores promoveram uma seleção dos textos originais com o intuito de apresentar aos leitores brasileiros os resultados de pesquisas avançadas no campo dos estudos gramscianos. Em função da realidade dos estudos gramscianos no Brasil, foram incluídos dois textos inéditos: Maquiavel como filósofo da práxis, de Francesca Izzo e Togliatti e Gramsci, de Giuseppe Vacca.

Guiseppe Vacca é também, o autor do prefácio da edição italiana, texto que apresenta o percurso dos seminários italianos de estudos nacionais e internacionais sobre o pensamento de Gramsci. Nele, discute a ação de aproximação e distanciamento entre o Instituto Gramsci e o Partido Comunista Italiano na organização dos seminários e no direcionamento das pesquisas sobre o pensamento de Gramsci. Fundamentado na leitura de Valentino 
Gerratana, Giuseppe Vacca destaca a ideia de que Gramsci é um pensador clássico do século $\mathrm{XX}$ que merece ser lido, relido e interpretado à luz de novos problemas, iniciativa contemplada pelo seminário de 1997, dedicado aos estudos sobre 'Gramsci e o século XX'. As pesquisas apresentadas, decorrentes de temas levantados nos seminários anteriores, enfatizavam a utilização dos conceitos de revolução passiva e crise orgânica, relançando o método histórico como chave interpretativa do pensamento de Gramsci.

O prefácio à edição brasileira, escrito por Alberto Aggio e Luiz Sérgio Henriques, foi intitulado de Gramsci no seu tempo - e no nosso. O texto reforça a ideia de que Gramsci é um clássico e de que o conceito de revolução passiva deve ser explorado como chave interpretativa do pensamento de Gramsci. Fundamentados no Caderno 15, os autores atualizam a leitura do pensamento de Gramsci, valorizam a dialética e a contextualização histórica como métodos interpretativos de seu pensamento, mas alertam para o fato de que não se pode sacralizá-lo, partindo do pressuposto de que não existe nada mais a ser estudado ou apreendido e advertem sobre as leituras apressadas que descolam o pensamento de Gramsci da matriz em que suas ideias foram produzidas.

A II Grande guerra, o pós-guerra, a renovação do socialismo e a filosofia da práxis são alguns dos temas que permeiam os textos que compõem a coletânea. A categoria hegemonia se entrecruza com outros conceitos do pensamento de Gramsci e constitui uma das chaves de leitura, ao lado do conceito de revolução passiva. Claudio Natoli e Andrea Panaccione utilizam o período do pós-guerra para analisar a renovação do socialismo, enquanto Francesco Auletta, Silvio Pons e Giuseppe Vacca discutem as relações de Gramsci com dirigentes do Partido Comunista Italiano, em especial com Palmiro Togliatti e Piero Sraffa.

A Filosofia da práxis é o conceito mediador que fundamenta os textos de Roberto Gualtieri, Fabio Frosini, Giuseppe Cospito, Giancarlo Schirru e Francesca Izzo. A economia e o americanismo mediam as análises de Terenzio Maccabelli e Alessio Gagliardi, que se direcionam à estrutura e ao corporativismo do regime político do fascismo na Itália. Por fim, destaca-se o texto de Anna Di Biagio, que explora a concepção de hegemonia nas propostas teóricas de Gramsci e Lênin.

O texto de Francesco Auletta, Piero Sraffa e Antonio Gramsci: l'Ordine Nuovo e as lutas operárias na Inglaterra e na América (1921), apresenta elementos significativos para a análise do cenário histórico das lutas operárias ocorridas no início da década de 1920. O texto explora a concordância de Sraffa com as teses de Gramsci, a partir das impressões que este tinha sobre os movimentos operários na Inglaterra e na América do Norte. Silvio Pons explora a divergência entre Gramsci e Togliatti no texto o Grupo dirigente do PCI e a 'questão russa' (1924-1926) e discute como as perspectivas ideológicas individuais influenciavam a percepção destes intelectuais sobre os desdobramentos da revolução proletária na Rússia. 
Em Hegemonia leninista, hegemonia gramsciana, Anna Di Biagio discute a relação entre a concepção de hegemonia cunhada por Gramsci e aquela atribuída à Lênin. Di Biagio destaca que, na experiência revolucionária russa, há uma estranheza entre as ideias de hegemonia e de democracia. Outro aspecto evidenciado é a perspectiva de que o conceito de hegemonia não faz parte do léxico habitual dos textos de Lênin, embora sua concepção de hegemonia já apresentasse as noções de direção política e direcionamento intelectual e moral. Di Biagio mostra que na ocasião do VIII Congresso do Partido Bolchevique, em 1919, não houve menção ao conceito de hegemonia nos escritos de Lênin ou no programa de partido, mas que, no período, pode ser constatado que Lênin se mostrava mais interessado em discutir e determinar a definição de ditadura do proletariado.

Fabio Frosini discute no texto $O$ neoidealismo italiano e a elaboração da filosofia da práxis, a influência do idealismo no pensamento de Gramsci e a sua transição teórica para o marxismo. As teorias dos liberais Benedetto Croce e Giovanni Gentille estão na gênese do pensamento do jovem Gramsci que dialogava com esses intelectuais, mas dos quais se distanciou gradualmente na medida em que, ao redigir os Cadernos do Cárcere, aprofundou suas análises sobre o fenômeno da religiosidade, da filosofia e do senso comum e se encaminhou para a fundamentação da Filosofia da Práxis.

Sob a influência do neoidealismo, Gramsci elaborou uma concepção de ideologia que pouco se distingue de sua concepção de filosofia. No Caderno 10, filosofia e ideologia foram apresentadas como uma mesma categoria histórica, distintas em função de seu grau. Enquanto a filosofia é uma concepção de mundo que representa a vida intelectual e moral de um grupo social, a ideologia é a concepção de mundo particular, pertencente aos grupos internos de cada classe que se propõem a solucionar os problemas sociais mais imediatos e restritos.

O texto de Francesca Izzo é o penúltimo da coletânea e explora a leitura de Gramsci sobre os escritos de Maquiavel e destaca que, ao redigir os Cadernos do Cárcere, Gramsci estava consciente de que a Europa não dominava mais o cenário mundial e que, os Estados Unidos e a URSS disputavam a primazia do controle hegemônico sobre os modelos políticos e econômicos. Izzo conclui que Gramsci entendia que no contexto histórico do século XX, o partido político assumiu o papel do príncipe e, na condição de líder coletivo, tinha a tarefa de criar uma nova organização ética e moral. Outra conclusão apontada por Izzo destaca que Gramsci defendia que os meios empregados na constituição do comunismo deveriam ser distintos daqueles empregados no nascimento do Estado Moderno, uma vez que em função da historicização da natureza humana, os fins e meios deveriam estar adequados à transformação dos homens e das relações sociais.

A contribuição de Giuseppe Vacca encerra a coletânea e termina reforçando a ideia inicial do texto: Gramsci é um autor clássico. Para apresentar tal afirmação de forma incisiva, Giuseppe Vacca discute a disputa intelectual entre Gramsci e Palmiro Togliatti, e 
apresenta aos leitores brasileiros o panorama histórico em que esta relação conturbada se desenvolveu. Com uma análise crítica fundamentada no panorama histórico, Giuseppe Vacca expõe a origem das divergências entre os dois teóricos do socialismo italiano. O texto é uma preciosa contribuição para a compreensão da relação entre Gramsci e Togliatti e da polêmica envolvendo a elaboração e publicação da primeira edição italiana dos cadernos de Gramsci. Giuseppe Vacca indica elementos preciosos para as investigações sobre o pensamento de Gramsci, destacando o conceito de revolução passiva como instrumento interpretativo de épocas históricas inteiras e indica que, na leitura de Togliatti, talvez intencionalmente, esse conceito não foi explorado.

Por fim, Giuseppe Vacca reconhece o mérito das ações de Togliatti que promoveram a imagem de um Gramsci ocidental e não apenas um pensador circunscrito à realidade italiana, e encerra o texto, a obra, indicando que o percurso percorrido por Togliatti, ainda que tortuoso, tinha como objetivo final reconhecer Gramsci como um clássico do século XX.

Gramsci no seu tempo é uma obra de grande interesse para pesquisadores da área das Ciências Humanas interessados no desenvolvimento do pensamento de Gramsci e nos desdobramentos do pensamento marxista no século XX. Se Gramsci teve o mérito de atualizar a leitura materialista da história e aperfeiçoar conceitos-chave para a análise dos fenômenos de ordem política, econômica e cultural, a presente obra promove uma apresentação contextualizada do pensamento de Gramsci e atualiza os leitores brasileiros a respeito do atual patamar das pesquisas sobre o pensamento gramsciano.

Com um bom projeto editorial, impresso em papel reciclado de ótima qualidade, a edição é valorizada ao apresentar as iniciativas de leitura do pensamento de Gramsci desenvolvidas na Europa. Ao empregar categorias analíticas até então pouco exploradas pelos pesquisadores brasileiros, Gramsci no seu tempo se consolida como uma referência de leitura àqueles que desejam avançar no universo da pesquisa sobre pensamento de Gramsci. A análise historicamente contextualizada apresentada nas páginas da coletânea serve de guia e fornece elementos históricos e conceituais para a leitura dos escritos de Gramsci e para a investigação sobre os principais fenômenos históricos da Itália na primeira metade do século XX. 